\title{
Separation and identification of Musa acuminate Colla (banana) leaf proteins by two-dimensional gel electrophoresis and mass spectrometry
}

\author{
Y. Lu ${ }^{1,2,3}$, Y.X. Qi ${ }^{1,2,3}$, H. Zhang, ${ }^{1,2,3}$, H.Q. Zhang ${ }^{1,2,3}$, J.J. Pu ${ }^{1,2,3}$ and \\ Y.X. Xie ${ }^{1,2,3}$ \\ ${ }^{1}$ Environment and Plant Protection Institute, \\ Chinese Academy of Tropical Agricultural Sciences, Hainan, China \\ ${ }^{2}$ Key Laboratory of Monitoring and Control of Tropical Agricultural and Forest \\ Invasive Alien Pests, Ministry of Agriculture, Haikou, Hainan, China \\ ${ }^{3}$ Key Laboratory of Pests Detection and Control for Tropical Agriculture, \\ Haikou, Hainan, China \\ Corresponding author: Y.X. Xie \\ E-mail: yixian81@126.com
}

Genet. Mol. Res. 12 (4): 6871-6881 (2013)

Received February 18, 2013

Accepted July 17, 2013

Published December 19, 2013

DOI http://dx.doi.org/10.4238/2013.December.19.6

\begin{abstract}
To establish a proteomic reference map of Musa acuminate Colla (banana) leaf, we separated and identified leaf proteins using two-dimensional polyacrylamide gel electrophoresis (2D-PAGE) and mass spectrometry (MS). Tryptic digests of 44 spots were subjected to peptide mass fingerprinting (PMF) by matrixassisted laser desorption/ionization time-of-flight (MALDI-TOF) MS. Three spots that were not identified by MALDI-TOF MS analysis were identified by searching against the NCBInr, SwissProt, and expressed sequence tag (EST) databases. We identified 41 unique proteins. The majority of the identified leaf proteins were found to be involved in energy metabolism. The results indicate that 2D-PAGE is a sensitive and powerful technique for the separation and identification of Musa leaf proteins. A summary of the identified proteins and their putative
\end{abstract}


functions is discussed.

Key words: Musa acuminate Colla; Proteomics; Two-dimensional gel electrophoresis; MALDI-TOF MS

\section{INTRODUCTION}

Two key steps in classical proteomics are the separation of proteins and their subsequent identification. In a standard approach, two-dimensional polyacrylamide gel electrophoresis and mass spectrometry are combined (Deutsch 2012). Two-dimensional PAGE, in which proteins are separated according to their isoelectric point in the 1st dimension and according to their molecular weight in the 2 nd dimension, remains the separation technique preferred by many researchers for global and comparative analyses of proteins. MS has essentially replaced the classical technique of Edman degradation in protein identification because it is more sensitive and can be used for protein mixtures and because it offers much higher throughput (Zuber et al., 2010). There are two main approaches to MS protein identification. In peptide mass fingerprinting, the unknown protein is digested with a protease of known specificity, such as trypsin. By determining the masses of the resulting peptides, a mass map or mass fingerprint can be obtained. This mass map is then compared with predicted mass maps of proteins within the database. The tandem mass spectrometric method relies on fragmentation of individual peptides to obtain sequence information (Smith, 2002; Yin et al., 2002; Huber and Rupasinghe, 2009).

Several plant proteomic studies have been published to date. Some have focused on organelle or subcellular proteomes, such as the chloroplast (Zybailov et al., 2009; Imad et al., 2011) or the mitochondria (Yamaguchi et al., 2002; Cui et al., 2011; Fuchs et al., 2011; Klodmann et al., 2011), whereas others have focused on a specific tissue, such as Arabidopsis seeds (Rajjou et al., 2008; Hélène et al., 2010), maize roots (Bhakti et al., 2009; Saleem et al., 2010), and maize leaves (Bhakti et al., 2009; Majeran et al., 2012). Large-scale projects for identifying proteins from multiple tissues of the barrel medic (Watson et al., 2003; Achref et al., 2011), rice (Fuhrs et al., 2010; Helmy et al., 2011), and Arabidopsis (Cui et al., 2011; Fernandez-Calvino et al., 2011) have also been reported.

Musa acuminate Colla (banana) is one of the most important food crops in the world and provides a staple food and source of income for many households. A protein reference map has not yet been reported for Musa leaf. As a 1st step to study the stress physiology of Musa, we separated and identified Musa leaf proteins from normal plants by using 2D-PAGE gels and matrix-assisted laser desorption/ionization time-of-flight MS.

\section{MATERIAL AND METHODS}

\section{Plant material}

Micropropagated Cavendish banana plantlets were obtained from the Musa Germplasm Center of Hainan. All plantlets were transplanted into plastic cups containing water, fertilized regularly with a nutrient solution, and were maintained in a greenhouse at $18^{\circ} / 25^{\circ} \mathrm{C}$ with a 16-h natural sunlight/8-h dark photoperiod. After 4 weeks, the plantlets developed a strong root structure and were transferred to an aeroponic system. Plants were watered daily. 
Four biological replicate samples were used for protein extraction and 2D-PAGE analysis. Samples were immediately frozen in liquid nitrogen and stored at $-80^{\circ} \mathrm{C}$ prior to analysis.

\section{Protein extraction from leaves}

Frozen leaf samples were homogenized to a fine powder using a pestle in a liquid nitrogen-precooled mortar. We used $500 \mathrm{mg}$ powdered tissue. The protocol was performed according to a study by Natarajan et al. (2005) with some modifications. The powdered tissue was suspended in $2.5 \mathrm{~mL}$ extraction buffer I (500 mM Tris- $\mathrm{HCl}, \mathrm{pH} 7.8,50 \mathrm{mM}$ ethelynediaminetetraacetic acid, $2 \% \beta$-mercaptoethanol, $2 \mathrm{mM}$ phenylmethanesulfonyl fluoride) and vortexed for $5 \mathrm{~min}$ at $4^{\circ} \mathrm{C}$. An equivalent volume cold Tris-buffered phenol, $\mathrm{pH}$ 7.8-8.0, was added and vortexed for $5 \mathrm{~min}$ at $4^{\circ} \mathrm{C}$ and centrifuged at $8000 \mathrm{~g}$ for $15 \mathrm{~min}$ at $4^{\circ} \mathrm{C}$. The phenol phase was recovered and precipitated with four volumes cold methanol and stored overnight at $-20^{\circ} \mathrm{C}$. After centrifugation at $8000 \mathrm{~g}$ for $15 \mathrm{~min}$ at $4^{\circ} \mathrm{C}$, the pellet was rinsed with cold methanol and centrifuged three times at 20,000 $\mathrm{g}$ for $5 \mathrm{~min}$ each at $4^{\circ} \mathrm{C}$. The pellet was air-dried, resuspended in the lysis buffer, and centrifuged at $20,000 \mathrm{~g}$ for $60 \mathrm{~min}$ at $4^{\circ} \mathrm{C}$. The supernatant was saved for analysis and stored in aliquots at $-80^{\circ} \mathrm{C}$.

\section{Protein quantification}

The protein concentration was determined using a Bio-Rad Protein Assay (Bio-Rad) with bovine serum albumin (BSA) as the standard.

\section{Two-dimensional gel electrophoresis}

2D-PAGE analysis was performed according to the Bio-Rad instrument operating manual. One hundred ninety grams sample protein was diluted with rehydration buffer ( $7 \mathrm{M}$ urea, 2 $\mathrm{M}$ thiourea, $65 \mathrm{mM}$ dithiothreitol (DTT), 4\% 3-[(3-Cholamidopropyl) dimethylammonio]-1-propanesulfonate (CHAPS), $0.5 \%$ immobilized $\mathrm{pH}$-gradient (IPG) buffer, $0.002 \%$ bromophenol blue) to a final volume of $350 \mu \mathrm{L}$ and rehydrated overnight onto IPG strips $(13 \mathrm{~cm}, \mathrm{pH} 3-10$; BioRad). The isoelectric focusing (IEF) assay was performed with the PROTEAN IEF Cell system (BioRad) at $20^{\circ} \mathrm{C}$ with a current limit of $50 \mathrm{~mA} /$ strip: $12 \mathrm{~h}$ at $50 \mathrm{~V}, 3 \mathrm{~h}$ at $300 \mathrm{~V}, 6 \mathrm{~h}$ at $1000 \mathrm{~V}, 3$ $\mathrm{h}$ at $5000 \mathrm{~V}$ (gradient), and 50,000 $\mathrm{Vh}$ at $10,000 \mathrm{~V}$. Before the 2 nd dimension separation, the IPG strips were equilibrated for $15 \mathrm{~min}$ in $10 \mathrm{~mL}$ equilibration buffer (6 M urea, 20\% glycerol, $2 \%$ sodium dodecyl sulfate (SDS), $0.002 \%$ bromophenol blue, $50 \mathrm{mM}$ Tris, $\mathrm{pH} 8.8$ ) containing $2 \%$ DTT, and subsequently for $15 \mathrm{~min}$ in $10 \mathrm{~mL}$ equilibration buffer containing $2.5 \%$ iodoacetamide. The 2nd dimension separation was performed on the PROTEAN II xi Cell system (BioRad) on $12 \%$ SDS polyacrylamide gels under the following conditions: $10 \mathrm{~mA}$ per gel for $30 \mathrm{~min}, 25 \mathrm{~mA}$ per gel for $7.5 \mathrm{~h}$. The gels were stained with the Silver Stain Plus Kit (Bio-Rad). The gel images were captured using the VersaDoc Imaging System (Bio-Rad) and analyzed using Image the Master 2-D Platinum v. 5.0 software (GE Biosciences, Uppsala, Sweden).

\section{Gel trypsin digestion}

Randomly selected spots were excised manually from the gels and transferred into 
$0.5 \mathrm{~mL}$ Eppendorf tubes. The samples were digested following the protocol described by Wang Ying with some modifications (Wang et al., 2006). Briefly, the spots were washed twice with distilled water and destained with $15 \mathrm{mM}$ potassium ferricyanide and $50 \mathrm{mM}$ sodium thiosulfate and dehydrated in acetonitrile (ACN) followed by $25 \mathrm{mM}$ ammonium bicarbonate. After re-dehydrating in ACN and drying, the proteins were digested overnight at $37^{\circ} \mathrm{C}$ with $10 \mathrm{mg} / \mathrm{mL}$ trypsin (Promega, Madison, WI, USA) in $25 \mathrm{mM}$ ammonium bicarbonate. Subsequently, the peptides were eluted from the gel plugs and extracted in $67 \% \mathrm{ACN} / 2.5 \%$ trifluoroacetic acid (TFA) and evaporated in a Speedvac (ThermoSavant, Milford, MA, USA).

\section{Mass spectrometry analysis}

Mass spectrum analysis was performed as described in the study by Quiala et al. (2012) with minor variations. The peptides were suspended in a minimal volume using sample diluent (30\% ACN/0.1\% TFA), deposited onto a MALDI plate, and analyzed with the 4800 plus MALDI TOF/TOF Analyzer (Applied Biosystems, Foster City, CA, USA). Alpha-cyano hydroxycinnamic acid (CHCA) was used as the matrix at $5 \mathrm{mg} / \mathrm{mL}$ in $50 \% \mathrm{ACN} / 0.1 \%$ TFA. A PMF was acquired in reflector mode in the mass range of 900-4000 Da, with an accelerating voltage of $20 \mathrm{kV}$. The seven most abundant ions from the MS analysis were subjected to MS/MS analysis. The 4700 Proteomics Analyzer Calibration Mixture (Applied Biosystems) was used as a standard in both MS and MS/MS procedures. The MS (PMF) combined with fragment mass (MS/MS) was analyzed using the GPS Explorer software (V3.6, Applied Biosystems) in the NCBInr database and using the MASCOT search engine (Matrix Science, London, UK). The search parameters were as follows: taxonomy restrictions to Viridiplantae (green plants), trypsin digest with one missed cleavage allowed, mass tolerance $=80 \mathrm{ppm}$, fragment mass $(\mathrm{MS} / \mathrm{MS})$ tolerance $=0.3 \mathrm{Da}$, variable modification $=$ carbamidomethyl $(\mathrm{C})$ and oxidation $(\mathrm{M})$, monoisotopic, and peptide charge $=+1$. Proteins with a score above the threshold $(\mathrm{P}<0.05)$ were considered to be positive.

\section{RESULTS}

\section{Separation of banana leaf proteins}

Protein extraction was performed according to a previously described protocol using phenol. We used immobilized $\mathrm{pH}$ gradient strip $(18 \mathrm{~cm}, \mathrm{pH} 3-10)$ with relative molecular masses of 10-120 kDa. The gel experiments were performed three times, and showed a high level of productivity. The arrowed and numbers in the figure refer to spots were identified. About 800 protein spots were detected on each gel using the PDQuest 7.1 software. A representative 2D-PAGE protein pattern of banana leaf is presented in Figure 1.

\section{Identification and functional classification of the proteins by MALDI-TOF MS}

The identified of the proteins were determined using MALDI-TOF MS. Forty-four proteins were identified, and showed in Table 1. All of the proteins identified were classed into 6 functional categories using the methods of Bevan et al. (1998): immunity and defense, 
energy/glycolysis/glyoxylate cycle/gluconeogenesis, energy/photosynthesis, metabolism, oxidation reduction, amino acid metabolism, and unknown (Figure 2). The most abundant proteins were including in the energy category, and some of these proteins appeared as multiple spots.

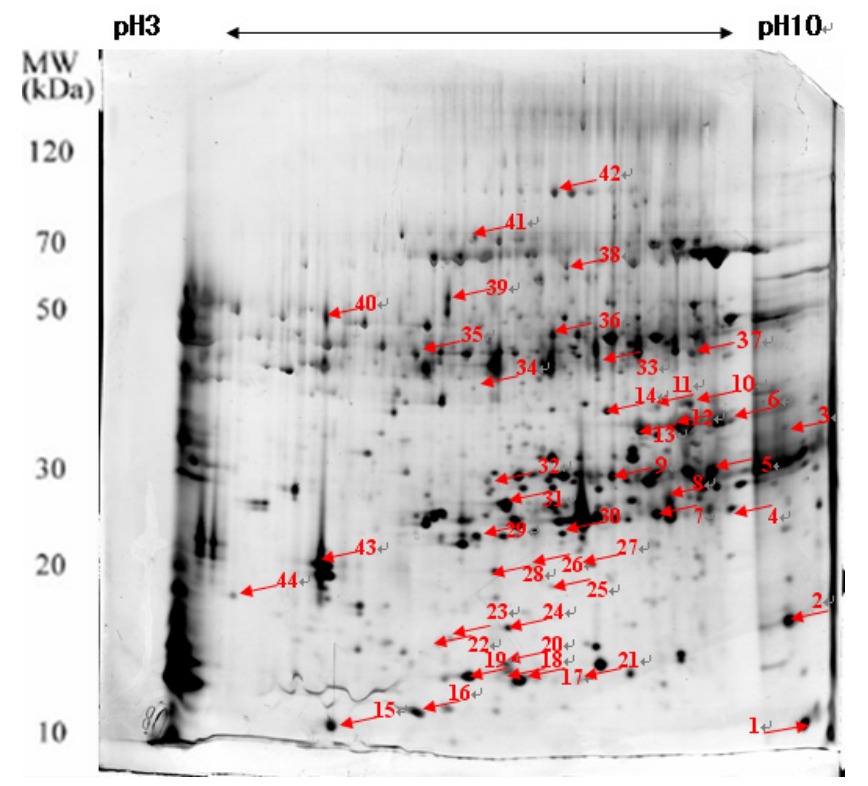

Figure 1. Coomassie-stained 2D-PAGE gel of separated banana leaf proteins. Proteins were separated in the 1st dimension on IPG strip $\mathrm{pH} 3.0-10.0$ and in the 2 nd dimension on $12.5 \%$ polyacrylamide SDS gel. The number of spots was identified, and the derived data are presented in Table 1.

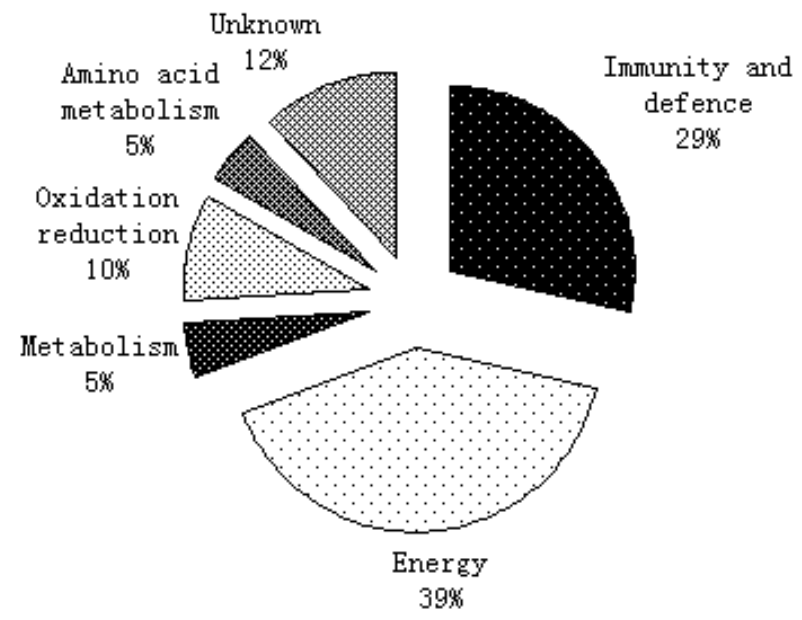

Figure 2. Assignment of the proteins identified to functional categories using the classification described by Bevan et al. (1998). A total of 41 spots representing 32 different proteins were classified. If a spot contained two proteins, it was counted twice. 


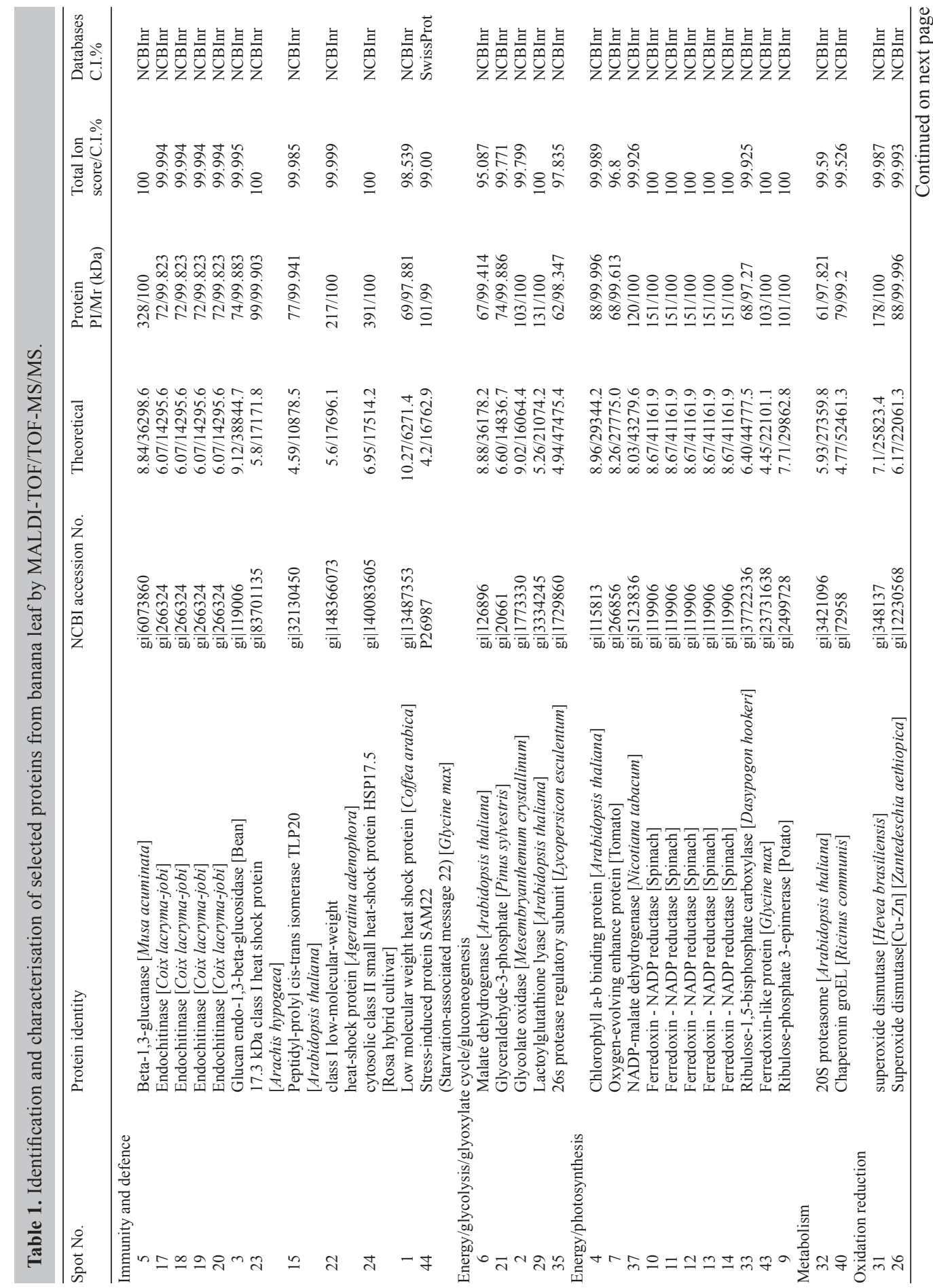


Musa proteins separated and identified by 2D-PAGE and MS

6877

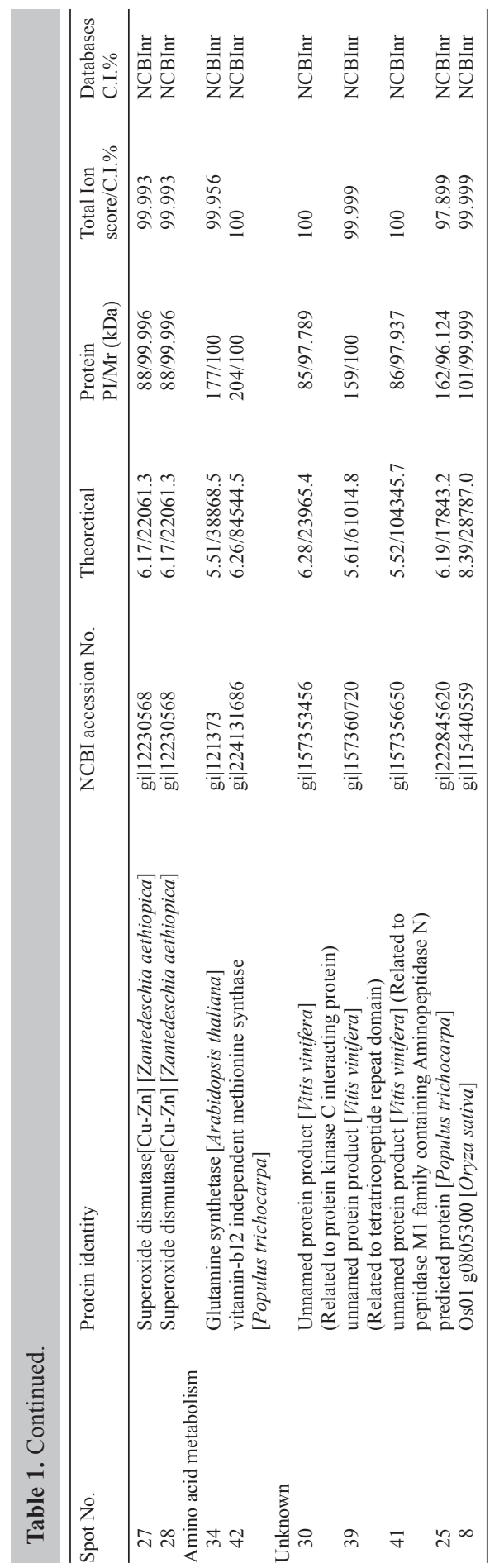

Genetics and Molecular Research 12 (4): 6871-6881 (2013) 
The proteins in involved in immunity and defense were beta-1,3-glucanase (spot 5), endochitinase (spots 17-20), glucan endo-1,3-beta-glucosidase (spot 3), low molecular weight heat shock proteins (spots 1,22 and 23), peptidyl-prolyl cis-trans isomerase (spot 15), and stress-induced protein SAM22 (spot 44). The identified proteins involved in glycolysis/glyoxylate cycle were Malate dehydrogenase (spot 6), Glyceraldehyde-3-phosphate (spot 21), Glycolate oxidase (spot 2), Lactoylglutathione lyase (spot 29), and 26s protease regulatory subunit (spot 35). Photosynthesis-related proteins included ferredoxins (spots 10-14 and 43), ribulose-1,5-bisphosphate (spot 33), chlorophyll a-b binding protein (spot 4), Oxygen-evolving enhance protein (spot 7), NADP-malate dehydrogenase (spot 37), and Ribulose-phosphate 3 -epimerase (spot 9). The proteins involved in metabolism were 20S proteasome (spot 32), and Chaperonin groEL (spot 40). The oxidation reduction-related proteins were superoxide dismutase (spot 26, 27, 28 and 31). Glutamine synthetase (spot 34), and vitamin-b12 independent methionine synthase (spot 42) were involved in amino acid metabolism.

Five proteins were classified as unknown. They are related to protein kinase C interacting protein (spot 30), related to tetratricopeptide repeat domain (spot 39), related to peptidase M1 family containing aminopeptidase N (spot 41), predicted protein (spot 25), and Os01 g0805300 (spot 8).

\section{DISCUSSION}

Extraction of proteins from plant tissues is a great challenge because they contain abundant of pigments and secondary metabolites (Koay and Gam; 2011). Banana leaves may contain a high level of polyphenols as well as other compounds that coprecipitation with proteins. We separated banana leaf proteins using a phenol-based protocol. The 2D-PAGE and subsequent mass spectrometry analysis demonstrated that the phenol-based protocol is a suitable method for extracting proteins from banana leaf. The use of phenol improves precipitation by reducing interference from other compounds in plant samples (Rose et al., 2004; Lei et al., 2007).

In the present study, approximately $49 \%$ of the identified protein spots were found to be involved in energy metabolism (Figure 2). The main function of a plant leaf is energy harvesting, conversion, and storage. Therefore, it is not surprising that a significant number of abundant proteins in the leaf proteome are involved in energy metabolism. Rubisco is the primary enzyme in photosynthetic carbon fixation and the likely rate-limiting factor for photosynthesis under light-saturated conditions and atmospheric $\mathrm{CO}_{2}$ pressure (Makino et al., 1985; Taiz and Zeiger, 2002).

Among the spots identified, 12 spots were found to be involved in immunity and defense. Immunity and defense proteins are stress-related and are important in cell activities, including stabilizing protein folding in response to stimuli, preventing denaturation or refolding of denatured proteins, and regulating many signal transduction pathways (Georgopoulos and Welch, 1993; Leone et al., 2000; Muccilli et al., 2009).

In this study, 12 proteins had multiple spots: endochitinase proteins (spots 17-20), ferredoxin-NADP reductase (spots 10-14), and superoxide dismutase (Cu-Zn) (spots 26, 27, and 28). Several factors may be responsible for this phenomenon. The migration of proteins on a 2D-PAGE gel is sensitive to small structural differences. These spots might be different isoforms derived from different genes of a multigene family. The complex genome of banana is expected to contain multiple copies of many genes, and the distinct biophysical properties 
might be due to amino acid sequence differences in the different isoforms. Alternatively, one gene product may undergo different co- and/or post-translational modifications that can affect its $\mathrm{pI}$ and/or Mr. The multiple spots corresponding to one protein could also be a consequence of artificial modification of proteins, such as carbamylation (Berven et al., 2003). However, appropriate precautions were used to prevent artificial modifications, and the multiple spots were reproducible. Therefore, it is unlikely that proteins were damaged during sample preparation.

Bioinformatic protein sequence analysis has shown that proteins with at least one transmembrane-spanning domain constitute approximately $20 \%$ of all proteins in the eukaryotic genome (Stevens and Arkin, 2000). These proteins are often underrepresented in 2DPAGE analysis because the hydrophobic transmembrane region can cause the proteins to precipitate during IEF (Molloy et al., 1998; Santoni et al., 2000). The presence of plant proteins in 2D-PAGE is relative to their average hydropathicity score (Millar et al., 2001). Most proteins identified in this study were expected to be soluble, given that phenol precipitation results in the loss of integral membrane proteins (Wang et al., 2000). Nevertheless, we found some spots that were identified as integral membrane proteins, such as chlorophyll a-b binding protein (spot 4) and oxygen-evolving enhanced protein (spot 7). These light-harvesting complexes are highly abundant in the thylakoid membranes of plant chloroplasts (Gomez et al., 2000). Therefore, a small fraction of these proteins was extracted during the sample preparation.

Banana is an important economic fruit in the tropics, and there are few studies related to the banana proteome. This is the 1st report of protein extraction from banana leaf, and the results will be useful for further banana proteomics studies.

\section{ACKNOWLEDGMENTS}

The authors would like to thank Dr. Huaping Li for the helpful discussion regarding the manuscript. The authors thank Miss Elizabeth Li for her help in revising this article. Funding for this research was provided by the China Agriculture Research System (\#CARS-32-04).

\section{REFERENCES}

Achref A, Ghislaine R, Franck R and Benoît S (2011). Arbuscular mycorrhizal symbiosis elicits shoots proteome changes that are modified during cadmium stress alleviation in Barrel Medic (Medicago truncatula). BMC Plant Biol. 11: 75.

Berven FS, Karlsen OA, Murrell JC and Jensen HB (2003). Multiple polypeptide forms observed in two-dimensional gels of Methylococcus capsulatus (Bath) polypeptides are generated during the separation procedure. Electrophoresis 24: 757-761.

Bevan M, Bancroft I, Bent E, Love K, et al. (1998). Analysis of $1.9 \mathrm{Mb}$ of contiguous sequence from chromosome 4 of Arabidopsis thaliana. Nature 391: 485-488.

Bhakti P, Alfredo SN, Paolo P and Maurizio C (2009). Evaluation of protein pattern changes in root and leaves of Zea mays plants in response to nitrate availability by two-demensional gel electrophoresis analysis. BMC Plant Biol. 9: 113.

Cui J, Liu J, Li Y and Shi T (2011). Integrative identification of Arabidopsis mitochondrial proteome and its function exploitation through protein interaction network. PLoS One 6: e16022.

Deutsch EW (2012). File formats commonly used in mass spectrometry proteomics. Mol. Cell. Proteomics 11: 1612-1621.

Fernandez-Calvino L, Faulkner C, Walshaw J, Saalbach G, et al. (2011). Arabidopsis plasmodesmal proteome. PLoS One 6: e18880.

Fuchs G, Diges C, Kohlstaedt LA, Wehner KA, et al. (2011). Proteomic analysis of ribosomes: translational control of mRNA populations by glycogen synthase GYS1. J. Mol. Biol. 410: 118-130.

Fuhrs H, Behrens C, Gallien S, Heintz D, et al. (2010). Physiological and proteomic characterization of manganese sensitivity and tolerance in rice (Oryza sativa) in comparison with barley (Hordeum vulgare). Ann. Bot. 105: 1129- 
1140.

Georgopoulos C and Welch WJ (1993). Role of the major heat shock proteins as molecular chaperones. Annu. Rev. Cell Biol. 9: 601-634.

Gomez S, Chitins PR, Yunus M and Pathre U (2000). Probing photosynthesis: Mechanisms, Regulation, and Adaptation. Taylor \& Francis, London, 51-69.

Helmy M, Tomita M and Ishihama Y (2011). Oryza PG-DB: Rice proteome database based on shotgun proteogenomics. BMC Plant Biol. 11: 63.

Huber GM and Rupasinghe HP (2009). Phenolic profiles and antioxidant properties of apple skin extracts. J. Food Sci. 74: C693-C700.

Imad A, Ardian C, John EF and Yue Y (2011). A J-like protein influences fatty acid composition of chloroplast lipid in Arabidopsis. PLoS One 6: e25368.

Klodmann J, Senkler M, Rode C and Braun HP (2011). Defining the protein complex proteome of plant mitochondria. Plant Physiol. 157: 587-598.

Koay SY and Gam LH (2011). Method development for analysis of proteins extracted from the leaves of Orthosiphon aristatus. J Chromatogr. B Analyt. Technol. Biomed. Life Sci. 879: 2179-2183.

Lei Z, Anand A, Mysore KS and Sumner LW (2007). Electroelution of intact proteins from SDS-PAGE gels and their subsequent MALDI-TOF MS analysis. Methods Mol. Biol. 355: 353-363.

Leone A, Piro G, Leucci MR, Zacheo G, et al. (2000). Membrane-cell wall-associated heat shock proteins in two genotypes of barley seedings. Plant Biosyst. 134: 171-178.

Majeran W, Friso G, Asakura Y, Qu X, et al. (2012). Nucleoid-enriched proteomes in developing plastids and chloroplasts from maize leaves: a new conceptual framework for nucleoid functions. Plant Physiol. 158: 156-189.

Makino A, Mae T and Ohira K (1985). Photosynthesis and ribulose-1,5-bisphosphate carboxylase/oxygenase in rice leaves from emergence through senescence. Quantitative analysis by carboxylation/oxygenation and regeneration of ribulose 1,5-bisphosphate. Planta 166: 414-420.

Millar AH, Sweetlove LJ, Giege P and Leaver CJ (2001). Analysis of the Arabidopsis mitochondrial proteome. Plant Physiol. 127: 1711-1727.

Molloy MP, Herbert BR, Walsh BJ, Tyler MI, et al. (1998). Extraction of membrane proteins by differential solubilization for separation using two-dimensional gel electrophoresis. Electrophoresis 19: 837-844.

Muccilli V, Licciardello C, Fontanini D, Russo MP, et al. (2009). Proteome analysis of Citrus sinensis L. (Osbeck) flesh at ripening time. J. Proteomics 73: 134-152.

Natarajan S, Xu C, Caperna TJ and Garrett WM (2005). Comparison of protein solubilization methods suitable for proteomic analysis of soybean seed proteins. Anal. Biochem. 342: 214-220.

Quiala E, Canal MJ, Rodriguez R, Yague N, et al. (2012). Proteomic profiling of Tectona grandis L. leaf. Proteomics 12: 1039-1044.

Rajjou L, Lovigny Y, Groot SP, Belghazi M, et al. (2008). Proteome-wide characterization of seed aging in Arabidopsis: a comparison between artificial and natural aging protocols. Plant Physiol. 148: 620-641.

Rose JK, Bashir S, Giovannoni JJ, Jahn MM, et al. (2004). Tackling the plant proteome: practical approaches, hurdles and experimental tools. Plant J. 39: 715-733.

Saleem M, Lamkemeyer T, Schutzenmeister A, Madlung J, et al. (2010). Specification of cortical parenchyma and stele of Maize primary roots by asymmetric levels of auxin, cytokinin, and cytokinin-regulated proteins. Plant Physiol. 152: 4-18.

Santoni V, Molloy M and Rabilloud T (2000). Membrane proteins and proteomics: un amour impossible? Electrophoresis 21: $1054-1070$.

Smith RD (2002). Advanced mass spectrometric methods for the rapid and quantitative characterization of proteomes. Comp Funct. Genomics 3: 143-150.

Stevens TJ and Arkin IT (2000). Do more complex organisms have a greater proportion of membrane proteins in their genomes? Proteins 39: 417-420.

Taiz L and Zeiger E (2002). Photosynthesis: the light reactions: In Plant physiology. Senauer Associates, 134-135.

Wang Y, Sun J and Chitnis PR (2000). Proteomic study of the peripheral proteins from thylakoid membranes of the cyanobacterium Synechocystis sp. PCC 6803. Electrophoresis 21: 1746-1754.

Wang Y, Cheung YH, Yang Z, Chiu JF, et al. (2006). Proteomic approach to study the cytotoxicity of dioscin (saponin). Proteomics 6: 2422-2432.

Watson BS, Asirvatham VS, Wang L and Sumner LW (2003). Mapping the proteome of barrel medic (Medicago truncatula). Plant Physiol. 131: 1104-1123.

Yamaguchi K, Prieto S, Beligni MV, Haynes PA, et al. (2002). Proteomic characterization of the small subunit of Chlamydomonas reinhardtii chloroplast ribosome: identification of a novel S1 domain-containing protein and 
unusually large orthologs of bacterial S2, S3, and S5. Plant Cell 14: 2957-2974.

Yin Y, Yu G, Chen Y and Jiang S (2002). Genome-wide transcriptome and proteome analysis on different development stage of Cordyceps milltaris. PLoS One 7: e51853.

Zuber H, Davidian JC, Wirtz M, Hell R, et al. (2010). Sultr4;1 mutant seeds of Arabidopsis have an enhanced sulphate content and modified proteome suggesting metabolic adaptations to altered sulphate compartmentalization. $B M C$ Plant Biol. 10: 78.

Zybailov B, Friso G, Kim J, Rudella A, et al. (2009). Large scale comparative proteomics of a chloroplast Clp protease mutant reveals folding stress, altered protein homeostasis, and feedback regulation of metabolism. Mol. Cell. Proteomics 8: 1789-1810. 